\title{
Natas
}

\section{Nota sobre San Marcos}

\author{
I N T ROD U C CION
}

El futuro destino del Perú depende, muy especialmente, de la educación que reciban sus nuevas generaciones. Los que en pasadas décadas fueron anónimos estudiantes sanmarquinos, dirigen la marcha actual del país en las ciencias físicas y humanas, en la política, en la administración etc. Y es natural que esto se repita, pero llama la atención que casi siempre lo olvidemos o actuemos como si lo hubiésemos olvidado.

En particular, nuestros estudiantes de Universidades y Escuelas Superiores constituyen un núcleo de-donde saldrá la clase directiva del país. Si desde ahora no los preparamos, la vida nacional sufrirá merma y cierto estancamiento, perceptible en hüestro siglo XX, cuande compórasenos con utrosfpaísesclatinoamericanos. Por esto, abordar el problema de nuestra educación superior significa vigilar el futuro de la nacionalidad.

Es de urgencia solucionar este problema en nuestra cuatricentenaria Universidad Nacional Mayor de San Marcos, por ser un centro docente de la mayor importancia cultural. Sus resultados, podrían ser aplicados a otras Universidades peruanas. Además, desde un punto de vista genérico, necesario es que, de una vez por todas, la Universidad se ponga al servicio de la ciencia, de la formación personal y profesional de los estudiantes y se convierta en una institución permanente de consulta para el Estado. Así, cumplirá su rectora función cultural y de progreso peruanista.

La fundamental diferencia - ya típica en San Marcos- entre el grupo tradicional, arcaico, y el grupo renovador, progresista, frente al 
planteamiento de los problemas universitarios y de su positiva solución estriba, más que en la enunciación de sus temas, en una clara diferencia de perspectivas, de puntos de vista, de actitudes. El grupo tradicional tiene una visión estática e inorgánica de lo que la Universidad es; por el contrario, el grupo renovador posee un sentido dinámico y funcional. Para aquéllos - grupo tradicional-, la Universidad es una institución cuyo mejoramiento depende de realizaciones parciales $e$ intermitentes, hechas en ciertos momentos "oportunos" por un individuo poco menos que insustituible; para éstos - grupo renovador-, la Universidad es una estructura compleja, orgánicamente entrelazada, cuyas necesidades básicas deben ser satisfechas en forma simultánea y progresiva, para bien general de la ciencia y del país.

Esta última posición, además apóyase en la firme creencia de que no sólo hay que manifestar lo que falta dentro de un modo orgánico y de perspectiva dinámica, sino que se debe luchar incansablemente por realizarlo de manera concreta. Porque de la educación eficiente 0 deficiente que imparta la Universidad depende el futuro del Perú, en un mundo contemporáneo donde es decisivo el papel de la ciencia en todo posible campo.

Reformar la Universidad peruana es viejo asunto, ya planteado desde el siglo XVI, cuando el mestizo peruano era planta novísima. Su presencia antigua y siempre nueva, acapara esfuerzos de muchísimas generaciones académicamentet insatisfechas Porque cuando la institución universitaria no sigue un ritmo natural de ininterrumpido proceso, sufre -y sufrirá- sacudimientos periódicos. Son lapsos de crisis que indican, felizmente, una vitalidad inadecuadamente canalizada y no una decadencia - que conduce a la extinsión.

Han existido, pues, constantes crisis en San Marcos como signos de una potente vitalidad, casi siempre no bien orientada. El año 1571, cuando la primera reforma laica - patrocinada por los miembros del claustro- sacó a la Universidad de su postración y la enrumbó hacía objetivos más amplios que los de una Universidad de facto intraclaustro. El año 1783, cuando el progresista catedrático de Vísperas de Leyes y co-precursor José Baquíjano y Carrillo encabezó un movimiento de reforma y fué estrechamente derrotado por tres votos. El año 1862, cuando el Rector Paz Soldán puso en marcha la moderna estructura de la Universidad. $Y$ en nuestro presente siglo, con numerosos y bien conocidos ejemplos.

Con ocasión de abordar aspectos relativos a nuestra Universidad Nacional Mayor de San Marcos - cuya actual situación es síntoma de algo más profundo, que debemos encarar con decisión-, serán alu- 
didos, de paso, cuestiones genéricas de las Universidades peruanas. Importa recordar aquí que, como institución dedicada a la educación superior, la Universidad de San Marcos - la más antigua de América, con un lastre algo mayor de cuatro siglos- en su pasado posee una cantera inagotable de incitaciones, desde la primera reforma universitaria - a los 20 años de fundada- hasta el presente, en que estaría redactado un Anteproyecto de Estatuto que derogaría el arcaico que nos rige.

\section{PLANTEAMIENTO DEL PROBLEMA}

Dentro de la educación superior - como se ha dicho con anterioridad- la Universidad persigue el cultivo del conocimiento críticocientífico - ya sea en el campo del mundo físico o del específicamente humano- con un interés nacional a la vez que universal, y la preparación profesional y académica, a la par que la formación personal de las nuevas generaciones peruanas.

Tales fines sugieren retornar a las fuentes primitivas de donde el problema brota, plantearlo en su básica simplicidad, necesaria para auyentar el ofuscamiento o añadidos innecesarios que impiden descubrir el mecanismo fundamental de lo que se quiere reformar.

La enseñanza universitaria - como la de otros grados educativosparte de una fundamental relación, que designaremos por $A-B$, caracterizada por la actividad de enseñar y de aprender (enseñar a... y eprender de ...) entre el Caledrático y el Estudiante; función que realiza la imprescindible actividad pedagógica de la vida académica. El uno (Catedrático) es predominantemente activo; el otro (Estudiante) es predominantemente pasivo. Porque sería nocivo que 0 uno o el otro fuesen absolutamente activo o pasivo, respectivamente.

Para que $A-B$ sea una actividad real, se cumpla de manera cotidiana, es necesario que haya un intermediario humano (colaborar tanto con... como con...) disciplinadamente organizado, cuyo representante es el Empleado. Lo designaremos brevemente por C. Hasta aquí, existe fundamentalmente una correlación humana: Catedrático-Estudiante-Empleado, cuya fórmula dinámicamente considerada sería $A-B-C$, con lo que se quiere significar que uno no sigue al otro en seriación topográfica, sino que cada uno influye recíprocamente sobre los demás.

Esta relación recíproca provoca una actividad compleja, actividad que se desarrollo en un lugar determinado. Pero aquí se trata de un lugar ad hoc, no de un sitio cualquiera. Esto plantea el problema de un edificio específicamente adecuado a la misión de la Universidad, no 
de postizas adaptaciones por urgencia o falta de previsión. Dicho nuevo factor será nominado por $D$.

La totalidad funcional $A-B-C-D$ es una estructura internamente coherente, pero necesitada de relaciones externas con estructuras institucionales análogas. Porque su renovación y actualidad -apoyada en un constante estrato histórico, de vida objetivada- depende, en gran parte, de un permanente intercambio cultural con instituciones afines y con las del Estado. Califícase este nuevo aspecto mediante $E$.

Instrumental al conjunto precedente, aparece el factor económico. De su mayor o menor potencialidad, deviene una mayor o menor posibilidad de actualizar sus fines - con factor humano de signo positivo, pues si su signo es negativo, también lo serán sus consecuencias. Llamaremos a este factor $F$.

Este grupo de factores: $A-B-C-D-E-F$, orgánicamente enlazados -porque tienen una presencia viva, desarrollada en el tiempo-, necesitan poseer un elemento normativo, algo que a su vez no varíe a capricho, no esté sujeto al vaiven de las circunstancias cotidianas. Surge entonces como una consecuencia - no como una causa- la necesidad de una legislación que presida la vida institucional en la forma de un Estatuto 0 de un Reglamento. Porque hay una entidad en marcha y periódica revisión, aparecen las normas -estancia axiológica derivada- metódicamente cambiables en determinados lapsos por necesidades de una realidad en proceso vital.

Contemplados los factores básicos de la Universidad -aparte de otros elementos complementarios, que aquinbeinteresan- necesario es preguntarse ¿cuáles aparecen como urgentes? Es obvio que los factores docente y económico exigen una imperiosa preferencia. Cabe, entonces, dar mayor énfasis a la situación del Catedrático y a la Economía universitaria, sin dejar de atender a los otros factores -durante una etapa də transición, hasta obtener una nivelación en otra realidad por venir. De aquí que en la siguiente parte brevemente analítica de esta nota, al lado de la sugerencia renovadora en plenitud, aparezcan recomendaciones transitorias, que permitan pasar de un inadecuado estado presente a otro adecuado estado futuro, a través de un aceptable lapso intermedio.

\section{SUGERENCIAS}

Se puntualizarán sintéticamente aspectos relativos a los factores básicos antes mencionados (A-B-C-D-E-F), con el propósito de echar una mirada a lo que San Marcos fué, a lo que es y a lo que podría ser. 


\section{I) El Catedrático}

Históricamente, hay dos regimenes, relacionados con dos etapas históricas del Perú: colonial y republicana. El Catedrático de la época virreinal tuvo un lapso primitivo poco preciso, desde la fundación de la Universidad hasta las reformas de la época de Toledo (1551-1571), con predominio docente del clero regular. Después, hasta finalizar el período colonial, hubo Catedráticos estables, dentro de una jerarquía de Catedrático de Prima (Principal Titular), de Vísperas (Principal Interino) y Regente (Catedrático Auxiliar). Predominó entonces el docente laico y otro perteneciente al clero secular. En la época republicana siguió análogo ritmo jerárquico, pero dentro de un régimen de horas. La docencia se hizo predominantemente laica. Los atisbos de profesionalización tienen su más acusado punto de partida en las reformas de 1931 y 1946. El precedente histórico está unido y es consecuencia del atraso social peruano. La Universidad colonial era -como tenía que ser- una institución de casta, destihada a los españoles-europeos (peninsulares) y a los españoles-americanos (criollos). Las otras castas - desde el mestizo- tenían prohibición - tácita y después expresạde estudiar en la Universiaad. Sin embargo, en la práctica pudieron ingresar mestizos, especialmente por la vía eclesiástica, y alguno que otro "pardo" o mestizo de negro por la vía de los estudios médicos. $\mathrm{Pe}$ ro esto significó siempre la excepción. Persistió el sentido de casta en la República, aunque fué imposible manifestarlo en forma pública porque el paso del régimen monárquico al republicano lo impedía, sentido de casta que ha ido desapareciendo lentamente. Pero se ha mirado la Cátedra, principalmente, por las ventajas sociales y políticas. De Rector se podía aspirar a la presidencia de la nación. El cultivo de la ciencia estaba relegado a un lugar secundario, salvo para una desesperante minoría, vista con amable tolerancia y hasta con ingenua suficiencia. Cuando un nuevo estudioso aparecía con autenticidad, era puesto de lado por el claustro, siendo entonces los intereses creados más fuertes, inclusive, que la posición social elevada porque se temía toda verdadera renovación. Hay que recordar, por ejemplo, que el sanmarquino José de la Riva Agüero no llegó a ser Catedrático Titular sino Adjunto en nuestra Universidad. Sin embargo, era muy superior a sus colegas de Facultad. Todas estas actitudes superviven todavía en el transfondo del actual problema universitario, porque cada institución como cada sociedad no puede librarse brúscamente de su pasado y exhibe supervivencias a la vez positivas y negativas. Hasta aquí, el pracedente histórico. 
Cada actividad arrastra consigo una determinada forma de vida. Cuando esto sucede se cumple una necesaria y estrecha correlación entre lo específico y lo genérico, dando como consecuencia una actividad cotidiana fecunda. Si se trata de una institución como la Universidad. compréndese cómo para que marche adecuadamente debe existir un personal docente dedicado por completo a la tarea de enseñar. Pero, ocurre que en la Universidad de San Marcos - y en las demás Universidades del país - la exigencia primaria entre la institución y la forma de vida del Catedrático no se cumple. Hay una clara heterogeneidad funcional.

Dentro de las actuales condiciones, urge hacer realidad el paso gradual del Catedrático no-profesionalizado al Catedrático dedicado al exclusivo servicio de la Universided, profesional de carrera ascendido a mérito de sus trabajos académicos y de su actividad magisterial. Ya el Catedrático meramente expusitivo y de limitado horario no satistace las específicas necesidades universitarias. Debe ser gradualmente sustituído por otro tipo de Catedrático, al total servicio de la institución. La clencia y la enseñanza universitaria exigen dedicación completa, un cierto desligamiento de múltiples actividades, si se quiere obtener resultados valederos.

Con el Catedrático de tiempo completo, se puede combatir las deficiencias de la actual enseñanza sanmarquina. Cabe afirmar que los objetivos primarios de su enseñanza harr sido parcialmente olvidados en aras de un afánicuantitativoede almacenar "conocimientos, inirttuitivamente recogidos en la mayor parte de los casos. Una meditación sobre las negativas consecuencias de dicha realidad, sería la mejor recomendación aconsejable. En realidad, descúbrese la presencia todavía actual de una añeja pedagogía que senilmente se aferra, pero que terminará por ser eliminada. Frente al deseo de acumular conocimientos, el ímpetu de leer sin tasa ni medida y exhibir seudoerudición, hay que insistir en un aprendizaje selectivo -apoyado en el examen de obras básicas, que permita evitar el atiborramiento y prematuro extravío. Frente a una pedagogía pasiva, el Catedrático profesionalizado alentará una pedagogía activa, a base de centros de interés del estudiante nuestro, con lo que entraremos en el auténtico rumbo de los fundamentales objetivos de la Universidad.

Por otra parte, un Catedrático de tiempo completo garantiza la buena preparación del Estudiante, defiende al cuerpo administrativo, contribuye al mejoramiento y conservación del local, supervigila su 
buena marcha económica, fomenta una activa relación con otras Universidades y contribuye a su mejoramiento genérico.

Cabe recordar - de paso- la existencia de cargos académicos superlativamente disminuídos. No hay relación entre la importancia de la tarea por realizar y su remuneráción. Como ejemplo, pueden señalarse los cargos de Director de Instituto y de Asesor de Tesis, cuyas asignaciones son tan bajas que mencionarlas sería despertar una superlativa hilaridad. Se carece de una transición económica aconsejable entre la función de Decano y la de Catedrático, representada por cargos académicos intermediarios suficientemente rentados. De aquí que cuando un Decano cesa, en la mayoría de los casos trata de jubilarse y la Universidad pierde colaboradores necesarios y eficientes.

Finalmente, hay que insinuar un procedimiento práctico de transición para lograr el objetivo propuesto. Puede comenzarse por otorgar una bonificación a los Catedráticos que no tengan otra renta que la proveniente de la enseñanza y cargo desempeñados en la Universidad. Es una manera de defender al Catedrático dedicado íntegramente a su servicio, carente de entradas complementarias. A continuación, podían ser considerados de horario corrido aquéllos que trabajan en Bibliotecas, Museos. Archivos o grados diversos de la enseñanza, por ser labor conexa con la actividad educativa superior. Y como hay notables Catedráticos, a los que la Universidad no podría pagar un equivalente de sus entradas externas, se mantendría paralelamente el fégimen de horas hasta su futura absorción. De esta manera se estimula la profesionalización del Catedrático. (Un experimento análogo ya está realizándose en la Educación Secundaria y en la Educacón Normal).

\section{II) El Estudiante}

El Estudiante sanmarquino $-\mathrm{y}$ el de las otras Universidades- ha sido y es, en gran parte, una persona que va a la Universidad sin estar plenamente en ella por motivos ajenos a su voluntad. Es un imprescindible elemento institucional, casi olvidado. Prima no un sentido formativo de su personalidad al servicio de una determinada especialización, sino una circunstancial tendencia acumulativa. La Universidari todavía no se interesa por la forma de vida que lleva, decisiva para el mayor o menor provecho de sus estudios.

Cuando examinamos los antecedentes literarios del Estudiante en la Universidad de San Marcos, hay grandes sorpresas y una cantera inagotable de sugerencias. Los Estudiantes de la época virreinal tenían una vida académica reglamentada, bajo la jurisdicción del Rector. Su exis- 
tencia cotidiana caía bajo la inmediata vigilancia de los Bachilleres de Púlpitos, funcionarios con representación oficial en las Constluciones - hoy, Estatutos- de la Universidad. Los Estudiantes tenían voto en la elección de Catedráticos; y los que poseían el grado menor de Bachiller estaban representados en los consejos del Rector. Tenía éste junto a sí cuatro Conciliarios: dos Doctores (Conciliarios Mayores) y dos Bachilleres (Conciliarios Menores). (Cir. las Constituciones de 1571, 1578, 1581, 1584, Añadidas de 1624, Recopilación de 1680 en su Tit. I, 1735, 1771 y Reglamento de 1816).

El Estudiante perdió sus privilegios en la época republicana y quedó relegado, apareciendo en determinados lapsos de endémicas protestas.

Urge un planteamiento justo respecto a su posición en la Universidad. No sólo se ha de exigir al Estudiante que estudie, sino que se le debe ayudar en sus problemas diarios para que pueda cumplir sus fines. La vida del universitario peruano está plagada de dramas cotidianos que la Universidad ignora -deliberadamente o no-, quedamdo truncas vocaciones por carencia de medios. La Universidad debe y tiene que interesarse por eliminar en todo momento el pauperrismo de sus estudiantes - base del ausentismo- y no exigir simple y ciegamente el cumplimiento de un aprendizaje sin proporcionarle medios para superar sus continuas dificultades. Un Estudiante defendido por la Universidad es el mejor colaborador de ellat; sus esfuerzos bien orientados serán una futura contribución lal desarello "científico y general del país. No hay peligro alguno de que colaboren en la marcha administrativa de la Universidad, y sean progresivamente incorporados - los más aptos- a la vida académica. Si la Universidad liberal no se preocupó del Estudiante, debemos desechar su herencia anacrónica y ayudarlos en los diversos años de estudio, estimularlos en sus trabajos para graduarse y organizar un Seminario permanente de Graduados de donde salga la futura docencia sanmarquina.

\section{III) El Empleado}

El problema concerniente al personal administrativo, es asunto por demás opacado en las diversas reformas universitarias republicanas. En las reglamentaciones virreinales se legisla en forma rutinaria lo concerniente a los "Oficiales" o cuerpo administrativo universitario. Genéricamente, se pueden distinguir cargos administrativos superiores -desempeñados por Catedráticos en su mayor parte-; cargos secun- 
darios, que llevan a los anteriores siempre que no se exija un grado académico - como es el caso del Secretario General; y cargos menores. Diverso el grado, pero con una común finalidad de colaboración institucional.

Ya es típica la presencia de un personal administrativo universitario mal remunerado, dentro de una administración inconexa. Como consecuencia brota un personaje agobiado por premiosas exigencias diarias, con un lastre negativo para cumplir sus tareas a entera satisíacción. Interesa sobremanera a la Universidad, para su buen funcionamiento orgánico, tanto administrativo como docente, tener colaboradores eficientes. Hay que acostumbrarse a considerar al Empleado universitario como a un importante colaborador dentro de una tarea común y no simplemente como el subordinado. Necesita para su mejor desempeño una ayuda directa e indirecta: progresivo aumento de haberes, Cooperativas de consumo -optativas para la docencia-, vigencia de todos los beneficios que acuerda la ley y otros procedimientos ventajosos que un examen pormenorizado permita enunciar. Defender al cuerpo administrativo de la Universidad -en sus diversos grados- significa defender la estabilidad cotidiana de la Universidad y su ininterrumpido funcionamento normal

IV) El Local

El problema dePlocal apropiado, donde la Universidad pueda desarrollar su actividad,oes punte de urgentenätención, de angustiosa necesidad en los momentos actuales, cuando impera una artificiosa estrechez que casi impide cumplir labores cotidianas de rango académico.

Es curioso recordar que las grandes reformas históricas de San Marcos har estado vinculadas a propósitos de mejoramiento del edificio universitario. Con ocasión de la primera reforma (1571), la Universidad salió del Convento de Santo Domingo y pasó a un nuevo local propio en San Marcelo, edificio que poco después resultaría estrecho e inadecuado. Con la nueva y decisiva reforma general, hecha por el virrey Toledo, San Marcos ocupó el local de la plaza de la Inquisición, lugar donde funcionó hasta la segunda mitad del siglo XIX. Puede afirmarse que, para la época, la Universidad de Lima tuvo un local apropiado. Al producirse la independencia, el Congreso tomó parte del edificio $y$, como consecuencia, vino una estrechez intolerable. Cuando al finalizar el segundo gobierno de Castilla, el Rector José Gregorio Paz Soldán reorganiza la Universidad, pasó ésta gradualmente 
al local del Convictorio de San Carlos -antiguo plantel de los jesuítas-, hecho que permite adquirir la necesaria comodidad a sus fines académicos. Este edificio aparente hasta comienzos del presente siglo, cada día se hace más insuficiente, a pesar de poseer San Marcos locales complementarios y haberse realizado obras de ampliación en su primitiva traza. De aqui que el proyecto de construir la Ciudad Universitaria - puesto en trance de ejecución con el Estatuto Universitario de 1946- sea una necesidad a corto plazo. (Una reseña del proceso mencionado, puede verse en el impreso denominado El actual Edificio de la Universidad Nacional Mayor de San Marcos por la Dra. Gred Ibscher y el suscrito).

Comenzada en forma poco adecuada, la Ciudad Universitaria debe continuarse de manera progresiva, dando prioridad a las necesidades más imperiosas. Urgente es construir las Facultades básicas de Letras y de Ciencias e ir dejando sitio en el viejo local hasta que la renovación gradual sea completa y nuestro actual edificio - respetando su valor histórico- se convierta en un Museo.

\section{V) Intercambio Universitario}

El problema de la Universidad y su relación con análogas instituciones académicas y con el Estado, constituye una actividad indispensable que no ha sido considerada en toda su importancia.

La Universidad ha estado siempre un poco de espaldas a los grandes problemas nacionales, salvo contadas circunstancias. No ha tomado parte y asesorado en los principales debates sobre aspectos de interés público desde sus diferentes Facultades especializadas. Tampoco ha propiciado ininterrumpidas reuniones anuales docentes, con sedes rotativas en el Cusco, Arequipa y Trujillo. Por esto, recíprocamente, el Estado ha dispensado casi siempre poca atención a su mejoramiento y hasta el limeño - que debía estar orgulloso de su decana Universidad de América- predominante la tiene en olvido. Lo cierto es que, como la más alta institución académica del país, San Marcos debía poseer un constante carácter consultivo en la solución de los problemas fundamentales del Perú.

Asimismo, la vida de San Marcos ha carecido, por cierta apatía directiva, de un precioso apoyo complementario de otras Universidades o instituciones culturales de tipo ecuménico. Esto se hace actualmente más perceptible si recordamos a la Asociación Mundial de Universidades - presidida por el Rector de la Universidad de París- y la Asociación Latinoamericana de Universidades - que preside el Rec- 
tor de la Universidad de Santiago de Chile. Mucho apoyo desapercibido pudo y puede ganar San Marcos con tales contactos permanentes para la economía de la Universidad, sus trabajos científicos, el mejo. ramiento de sus Catedráticos y el perfeccionamiento de los Estudiantes.

\section{VI) La Economía Universitaria}

Corre el mito de la pobreza de San Marcos. Sin caer en el concepto opuesto de opulencia, puede afirmarse que la Universidad tiene una posición económica muy respetable, siempre que en el dia sean revalorados sus bienes y se maneje su economía con el interés financiero de acrecentarlos.

Un derrotero documental puede obtenerse en el Departamento Jurídico de la Universidad. Puede también hacerse una reseña escueta, tomando como base los Libros de Tesorería coloniales del Archivo Central y documentos contemporáneos de la Tesorería. Muchos datos importantes hay en el Archivo Nacional y en el Archivo del Ministerio de Hacienda y Comercio. Entre algunos impresos, pueden mencionarse el Presupuesto y Programas de Estudio de la Universidad de San Marcos (Lima 1862), el Margesí de los Bienes de la Universidad Mayor de San Marcos (Lima 1907), el Inventario General de Bienes (Lima 1934), etc.

Puede afirmarse que los bienes dela Universidad han sido y son todavía cuantiosos, aunque hocadministrados conocriterio comercial de acrecentamiento. (Recuérdese el margen positivo que dejará la plusvalía con las retasaciones de inmuebles). Una inmediata revisión económica de los bienes sanmarquinos se hace urgente. Correría a cargo de una Comisión ad hoc, rentada, que presente su Informe en un determinado plazo. Porque con una clara noción del actual poder económico de San Marcos, sería más fácil estructurar un plan reformista de valor objetivo y lograr la realización de una reforma económica que permita a la Universidad obtener de sus bienes un adecuado rendimiento.

\section{VII) Reglamentación Universitaria ...}

La legislación encauza algo ya existente. Sirve no para crear situaciones, sino para normarlas. Porque hay un proceso real, se necesita una legislación apropiada que cautele su desarrollo. Lo que supone, que se debe considerar una legislación como consecuencia -no como causa. Cabe recalcar esto especialmente en el Perú, donde pecamos de un ingenuo y exagerado optimismo normativo. 
En la actualidad rige el Estatuto de 1942, arcaico en demasía, derogatorio del Estatuto de 1946, que significó un avance y una renovación. Se habla de un Anteproyecto de Estatuto Universitario que, seguramente, aportará modificaciones benéficas. Quizá sería mejor redactar un nuevo Anteproyecto genérico, con disposiciones básicas que estén fuera del vaivén de las circunstancias. La totalidad de nuestros Estatutos son, en realidad, Reglamentos. Pero, ante todo, urge previa o simultáneamente modificar la vida universitaria en su estructura general, si se desea que el futuro Estatuto universitario tenga una aplicación efectiva. En caso contrario no pasará de ser una norma más, con muy buenas intenciones pero inefectiva.

\section{O N GL US I O N}

En síntesis, la Universidad de San Marcos debe enfocar, de manera simultánea, la totalidad de sus problemas básicos. Sería improductivo encarar determinados casos aislados. Sin embargo, dentro de esta perspectiva funcional, cabe darse predominio al problema docente y al económico.

A nadie conviene -ni le puede convenir- que San Marcos permanezca en el estancamiento actual. El país lo necesita, los catedráticos lo desean, las nuevas generaciones universitarias lo requieren, el cuerpo administrativo Jo anhela.c Cualquiero contrario interés atenta contra la seguridad y progreso futuros del Perú que, fundamentalmente, descanza en en la eficiente preparación que impartan los maestros a las nuevas generaciones que dirigirán el Perú.

Daniel Valcárcel. 